\title{
Status of General Practice and Challenges to Healthcare System of Pakistan
}

\author{
Rashid M. Ansari ${ }^{*}$, Yusra Ansari², Saiqaa Y. Ansari1 \\ ${ }^{1}$ Department of General Practice, School of Primary Health Care, Monash University, Melbourne, Australia \\ ${ }^{2}$ Rawalpindi Medical College, Islamabad, Pakistan \\ Email: *rashid.ansari@monash.edu
}

Received 14 November 2015; accepted 15 December 2015; published 18 December 2015

Copyright (C) 2015 by authors and Scientific Research Publishing Inc.

This work is licensed under the Creative Commons Attribution International License (CC BY). http://creativecommons.org/licenses/by/4.0/

(c) () Open Access

\section{Abstract}

This article provides insight into the status of general practice in Pakistan and challenges to its health care system. The country ranked $122^{\text {nd }}$ on the overall health system attainment and ranked $7^{\text {th }}$ in the world on diabetes prevalence. The public sector health care system in Pakistan is encountered with many problems such as structural fragmentation, resource scarcity, inefficiency and lack of functional specificity, gender insensitivity and inaccessibility. The general practice status in Pakistan requires immediate attention to face the challenges created by chronic diseases in the country. Of particular mention are the patient-doctor interaction, healthcare system delivery, access to the doctors and better utilization of primary health care services.

\section{Keywords}

General Practice, Healthcare System, Type 2 Diabetes, Challenges from Chronic Diseases, Gender Disparity, Low Ranking

\section{Introduction}

General practice is widely regarded as being at the heart of both the primary health care system and the health system overall and GPs play a crucial role as "gateways" to the rest of the medical system [1]. The healthcare system of Pakistan is facing many serious problems such as inequity, gender differences and unskilled human resources and overall mismanagement of health care system. The $0.8 \%$ of GDP on health care system is far less than the neighbouring countries such as Bangladesh (1.2\%) and Sri Lanka (1.4\%) [2]. In order to improve the overall health status of the people, poor indicators of health in the region, Pakistan Government initiated the health care reforms in 2001. Keeping in view the poor performance of healthcare system of Pakistan, the World

\footnotetext{
*Corresponding author.
} 
Health Organization (WHO) ranked Pakistan $122^{\text {nd }}$ in overall health system performance among 191 countries [3] [4]. The health indicators, health funding, and health and sanitation infrastructure are generally poor in Pakistan, particularly in rural areas.

The statistics show that there are 127,859 GPs and 12,804 health facilities in the country to cover for over 170 million people [5]. There were 85 physicians for every 100,000 persons in Pakistan in 2007 that is one doctor for 1225 people. Ministry of Health Pakistan statistics indicated that, there were 13,937 health institutions in the country including 945 hospitals (with a total of 103,285 hospital beds), 4755 dispensaries, 5349 basic health units (mostly in rural areas), 903 mother and child care centers, 562 rural health centers and 290 TB centers [6] [7]. There is an inequitable distribution of GPs in the country, with 70\% practicing in urban areas where only 30\% of the population lives: in addition, only $10 \%$ to $15 \%$ of GPs in rural areas are females [8].

\section{GPs Interaction with the Population}

The nature of population seen by GPs in the rural area of Peshawar, Pakistan includes females accounted for 53\% of encounters, and the greater proportion of encounters in all adult age groups. Children (aged $<15$ years) accounted for 15\% of encounters, those aged 15 - 24 (5\%), 25 - 44 (19\%), 45 - 64 (30\%), 65 - 74 (10\%), and 75 and over (5\%) [6] [7]. The other patient's encounters belong to refugee camps and other rural areas which do not speak the local languages. At 2\% of encounters the patient identified themselves as Afghani's temporarily residing in Pakistan nearthe Pak-Afghan border.

\subsection{Trends Encountered}

About 19 percent of the population is malnourished of which 30 percent of children under age five are malnourished. The leading causes of sickness and death include gastroenteritis, respiratory infections, congenital abnormalities, tuberculosis, malaria, and typhoid fever. The United Nations estimated that in 2003 Pakistan's HIV prevalence rate was 0.1 percent among 15 - 49, with an estimated 4900 deaths from AIDS. Hepatitis B and C are also rampant with approximately 3 million cases of each in the country at the moment. The burden of disease due to communicable and non-communicable disease is $52.8 \%$ and $39.4 \%$ respectively with total DALY's 56.1\% and 34.2\% [4]. Table 1 and Table 2 provide more details on burden of disease, including the child health statistics in Pakistan. For example, Respiratory infection is the leading cause of death with $10.5 \%$ total DALYs. Among the non-communicable diseases, CVD is the main cause of deaths with $20.7 \%$ of the total deaths with $20.2 \%$ total DALY's.

\begin{tabular}{ccc}
\hline \multicolumn{3}{c}{ Table 1. Burden of disease due to communicable and non-communicable disease. } \\
\hline Communicable, maternal, and perinatal conditions & 52.8 (\% total deaths) & 56.1 (\% total DALYs) \\
\hline Diarrheal diseases & 8.5 & 8.7 \\
Respiratory infections & 12.1 & 10.5 \\
Maternal conditions & 1.7 & 3.4 \\
Perinatal conditions & 8.2 & 9.8 \\
Low birthweight & 5.9 & 6.6 \\
Nutritional deficiencies & 1.5 & 3.1 \\
Non-communicable diseases & 39.4 & 34.2 \\
Cancers & 5.6 & 2.1 \\
Diabetes mellitus & 1.2 & 0.8 \\
Neuropsychiatry & 1.8 & 10.1 \\
Cardio-vascular diseases & 20.7 & 20.2 \\
Injuries (the road traffic injuries) & 7.8 & 9.7 \\
\hline
\end{tabular}

Source: Mathers et al. [4]. 
Table 2. Child health status in Pakistan.

\begin{tabular}{ccc}
\hline Child health & $1990-1991$ & $2006-2007$ \\
\hline Neonatal mortality rate & $51.4 \%$ & $54 \%$ \\
Infant mortality rate & $90.5 \%$ & $78 \%$ \\
Immunization status & $21.8 \%$ & $47.3 \%$ \\
Health seeking behaviour & & \\
Acute respiratory infections & $66.4 \%$ & $69.3 \%$ \\
Fever & $64.8 \%$ & $65.8 \%$ \\
Diarrhea & $48.3 \%$ & $54.5 \%$ \\
\hline
\end{tabular}

Source: Pakistan Demographic \& Health Survey (1990-1991; 2006).

\subsection{Problems Managed}

On the average, chronic problems accounted for $48 \%$, and new cases for $40 \%$ of all the problems. The work related problems managed at a rate of 1.2 per 100 encounters. The most commonly managed problems are respiratory problems, problems of a general and unspecified nature, orthopedic related, skin disease and cardiovascular. Individual problems managed are diabetes and upper respiratory tract infection. The prevalence of Type 2 diabetes in Pakistan is high ranging from 7.6\% (5.2 million populations) to 11\% [9] and for 2030 it will increase to around $15 \%$ (13.8 million populations) and as such Pakistan is ranked $7^{\text {th }}$ on diabetes prevalence list [10] and it is among the top 10 countries in the world for people with diabetes aged 20 - 79 years [11].

\subsection{Medications Prescribed}

The specific data on medications/encounter could not be obtained or perhaps was not developed. However, the most prescribed medications were related to diabetes that accounted for more than $60 \%$ of problems managed by GPs (Pakistan ranked $7^{\text {th }}$ on diabetes prevalence list) [10]. The other medications types most often prescribed were those related to depression and cardiovascular diseases and for high cholesterol problems (lipid profile). The most commonly prescribed medications were antibiotics, antacid and stomach problems related such as peptic ulcers, diarrhea, respiratory infections and maternal conditions.

\section{The Structure of Primary Care Services}

The public sector health care system in Pakistan is encountered with many problems such as structural fragmentation, resource scarcity, inefficiency and lack of functional specificity, gender insensitivity and inaccessibility [12]. The 66\% population living in rural areas face inadequately organized primary care services which are slowing down progress in health indicators [13].

In Pakistan, for each basic unit there are 10 staff members and approximately an average of 20 - 25 patients per day are seen by the doctors in each unit. There is not much progress in primary care delivery system over the last three decades. A recent national survey has indicated that only $20 \%$ of the people used the first level public sector network for their health care needs [7] [14]. Therefore, the primary care was unleased to contracting services in Pakistan to overcome the economic constraints and inability to deliver public goods [15]. It was observed that by using the primary care contracting concepts and implementation in one of the cities in Pakistan, the situation in the city was improved in terms of utilization of basic health services, community satisfaction, out of pocket expenditure and quality of care. It is anticipated that this contracting of primary health care service will be extended in future to rural areas of Pakistan as well to see the benefits of it in those regions as well.

\section{Utilization of Primary Care Services}

The utilization of primary health clinic in Pakistan is not well planned and organized. The diabetes management for example, is mostly integrated into the public health system through primary health care. Usually, people with diabetes are referred from primary health-care clinics to specialist diabetes centers because the healthcare interventions to manage diabetes cases starts with the registration of the patient in a primary health care clinics and 
the issuing of diabetes card. Medical diagnosis includes a physical examination and laboratory studies.

These clinics in Pakistan do not conform to the evidence-based quality standards as compared to the targets established by the American Diabetes Association [16] and therefore face great challenges to provide diabetes care.

\section{Patterns of Morbidity in Population}

Morbidity is a multidimensional concept, and time trends in the different dimensions can vary [17]. Increases in physiological dysregulation, disease onset, functioning loss, and frailty are all parts of the process of health change that can precede death [18].

The patterns of morbidity in the population include cardiovascular diseases, chronic obstructive pulmonary disease, heart failure, diabetes and depression. CVD is a major cause of morbidity in this population followed by diabetes and its complications. This population has two levels of trends in morbidity namely the macro level and micro level which has triggered changes to primary health care in this population. At a macro level, the trends included an increase in ageing population with chronic and complex diseases and require comprehensive care. At a micro level, the trends increased in coordinating care, managing the comorbidity and teams and making the time to build trust and relationship [19]. These patterns of morbidity have an overall impact on our practice in terms of maintaining the important characteristics of primary health care. These changes in primary health care are posing great challenges to our team and require developing primary health care research to address the challenges of care for people with comorbidities.

\section{Financing of Primary Care}

In Pakistan, only 3.1\% of the total annual budget is allocated for economic, social and community services, and $43 \%$ is spent on debt servicing [14]. In most of the developing countries of South Asia, out-of-pocket household expenditure on health is at times as much as $80 \%$ of medical expenditure [20]. For health expenditure in Pakistan, it is about US \$17 per head per year, out of which \$13 is out-of-pocket private expenditure [13]. The country spends $80 \%$ of its health budget on tertiary care services, which are utilized by only $15 \%$ of the population. In contrast, only $15 \%$ is spent on primary health care services, used by $80 \%$ of the population [21].

\section{Conclusion}

This has been demonstrated in this review article that general practice status in Pakistan requires immediate attention to face the challenges created by chronic diseases. Pakistan health care system requires national policies to provide efficient, effective, acceptable, cost effective, affordable and accessible services to its population. Pakistan needs to address the issues related to shortages of community doctors and expensive consultation of doctors to allow for more access of the patients to the doctors and to help the population in managing the diabetes and other chronic diseases. A coordinated effort is also required to address the comorbidity challenges in the population of Pakistan.

\section{Conflict of Interest Statement}

The authors declare that there are no conflicts of interest.

\section{References}

[1] Pirkis, J.E., Blashki, G.A., Murphy, A.W., et al. (2006) The Contribution of General Practice Based Research to the Development of National Policy: Case Studies from Ireland and Australia. Australia and New Zealand Health Policy, 3 , 4. http://dx.doi.org/10.1186/1743-8462-3-4

[2] World Bank (1999) World Development Report 1998/99: Knowledge for Development. Oxford University Press, New York.

[3] WHO (2000) The World Health Report 2000. Health Systems: Improving Performance. World Health Organization, Geneva.

[4] Mathers, C.D., Lopez, A.D. and Murray, C.J.L. (2006) The Burden of Disease and Mortality by Condition: Data, Methods and Results for 2001. Oxford University Press, New York.

[5] World Population Prospects (2014) The 2006 Revision Population Database, Accessed Online at http://esa.un.org on 
Nov. 14, 2000. International Data Base, Accessed Online at www.census.gov, on March. 2014.

[6] Shaikh, B.T. and Hatcher, J. (2004) Health Seeking Behaviour and Health Service Utilization in Pakistan: Challenging the Policy Makers. Journal of Public Health, 27, 49-54. http://dx.doi.org/10.1093/pubmed/fdh207

[7] National Institute of Population Studies (NIPS) (2007) National Institute of Population Studies and Measure DHS, Pakistan Demographic and Health Survey 2006-07: Preliminary Report. Macro International Inc., Calverton.

[8] Khan, N.J. and Hall, S.E. (2001) The Determinants of Reproductive Health Service Provision by General Practitioners in Pakistan. Health Policy and Planning, 19, 209-217. http://dx.doi.org/10.1093/heapol/czh026

[9] Jafar, T.H., Chaturvedi, N. and Pappas, G. (2006) Prevalence of Overweight and Obesity and Association with Hypertension and Diabetes Mellitus in an Indo-Asian Population. CMAJ, 175, 1071-1077. http://dx.doi.org/10.1503/cmaj.060464

[10] (2013) World Health Organization’s Evidence for Health Policy: Health System Performance, Geneva. [On-Line.] http://www.who.int/health-systems-performance/

[11] International Diabetes Federation (2012) Diabetes Prevalence. http://www.idf.org/home/index.cfm

[12] Shaikh, B.T., Rabbani, F. and Safi, N. (2010) Contracting of Primary Health Care Services in Pakistan: Is Up-Scaling a Pragmatic Thinking? Journal of Pakistan Medical Association, 60, 387-389.

[13] Word Bank (2002) Pakistan-Poverty Assessment: Poverty in Pakistan-Vulnerabilities, Social Gaps, and Rural Dynamics. Poverty Reduction and Economic Management Sector Unit, South Asia Region.

[14] Government of Pakistan-GP (2000) Ministry of Finance. Budget 2001-2002. Finance Division.

[15] Nishtar, S. (2006) The Public-Private Interface: More than “a Driver’s Economic Growth”. View Point: Pakistan Health Policy Forum, Heartfile, Islamabad.

[16] American Diabetes Association (2009) Standards of Medical Care in Diabetes—2009. Diabetes Care, 23, S13-S61. http://dx.doi.org/10.2337/dc09-S013

[17] Crimmins, E.M. (1996) Mixed Trends in Population Health among Older Adults. Journal of Gerontology: Social Sciences, 51, S223-S225. http://dx.doi.org/10.1093/geronb/51B.5.S223

[18] Martin, L., Freedman, V.A., Schoeni, R., et al. (2010) Trends in Disability and Related Chronic Conditions among People Ages Fifty to Sixty-Four. Health Affairs, 29, 725-731. http://dx.doi.org/10.1377/hlthaff.2008.0746

[19] Starfield, B. (2003) Primary and Specialty Care Interfaces: The Imperative of Disease Continuity. British Journal of General Practice, 53, 723-729.

[20] World Bank (1998) Raising a Healthier Population. South Asia Brief. Washington DC.

[21] Hunte, P. and Sultana, F. (1992) Health-Seeking Behaviour and the Meaning of Medications in Baluchistan, Pakistan. Social Science \& Medicine, 34, 1385-1397. http://dx.doi.org/10.1016/0277-9536(92)90147-I 